\title{
The Effect on Starch Pasting Properties and Predictive Glycaemic Response of Muffin Batters Using Stevianna or Inulin as a Sucrose Replacer
}

\author{
Jingrong Gao, Han Fezhong, Xinbo Guo, Xi-An Zeng, Susan L. Mason, \\ Margaret A. Brennan, and Charles S. Brennan*
}

Different levels of sugar replacers (inulin or Stevianna) are used in two muffin batter recipes differing in sugar:flour ratios. The properties of these sugar replacers are linked to differences in batter viscosity, starch gelatinization, and in vitro predictive glycemic response of batters. The replacement of sugar with Stevianna has no significant effect on the viscosity of the batter or the starch gelatinization. Replacement of $50 \%$ or more of the sugar with inulin increased batter viscosity. The starch gelatinization properties were altered with the incorporation of inulin. Batters incorporating Stevianna and cocoa powder has significantly different viscosity compared to the batters incorporating Stevianna without cocoa powder. In vitro starch hydrolysis of the batters illustrate that the inclusion of inulin or Stevianna significantly reduce the rate and extent of carbohydrate hydrolysis doing digestion.

\section{Introduction}

Muffin batters are complex fat-in-water emulsion systems containing flour, starch, sugar, fat, eggs, and baking powder. The biochemical and physicochemical reactions which occur during baking are complex and involve water evaporation, protein denaturation, starch destruction, browning and Maillard reactions, dough expansion by production, and thermal expansion of gas during batter processing. ${ }^{[1]}$ Starch gelatinization plays an important

\author{
J. Gao, Dr. S. L. Mason, Dr. M. A. Brennan, Prof. C. S. Brennan \\ Department of Wine, Food Molecular Biosciences \\ Lincoln University \\ Lincoln, New Zealand \\ E-mail: charles.brennan@lincoln.ac.nz \\ J. Gao, Prof. C. S. Brennan \\ Riddet Institute \\ Palmerston North, New Zealand \\ Dr. H. Fezhong, Dr. X. Guo, Dr. X.-A. Zeng \\ College of Light Industry and Food Science \\ South China University of Technology \\ Guangzhou 510640, Guangdong, China
}

(C) 2018 The Authors. Starch - Stärke Published by WILEY-VCH Verlag $\mathrm{GmbH} \& \mathrm{Co} . \mathrm{KGaA}$, Weinheim. This is an open access article under the terms of the Creative Commons Attribution-NonCommercial-NoDerivs License, which permits use and distribution in any medium, provided the original work is properly cited, the use is non-commercial and no modifications or adaptations are made.

DOI: 10.1002/star.201700334 role in baked foods with swelling and pasting influencing product structure. Differential scanning calorimetry (DSC) is a powerful tool for changing of starch gelatinizes in thermal properties being heated or cooled at a constant rate. The batter viscosity is investigated with a rapid visco analyzer (RVA) and related to the quality of baked products. The batter needs to be sufficiently viscous to trap gas bubbles during mechanical mixing and during heating. ${ }^{[2]}$ Another fundamental requirement for baked products is that most of the swollen starch granules retain a recognizable granular shape, and be strong enough to be self-supporting when the baked product is removed from the oven. ${ }^{[3]}$

Sugars function as main ingredients in muffin. It can increase the temperature at which starch gelatinizes by interacting with the starch and forming bridges between starch chains. Psimouli and Oreopoulou $^{[4]}$ reported that sugar limits the available water, thereby lowering water activity. Starch gelatinization increases the viscosity of the batter considerably, which strengthens the batter structure leading to the depression of bubbles. ${ }^{[5]}$ Therefore, more air bubble development may occur when starch gelatinization occurs at higher temperatures thus allowing the development of a porous structure in the final product. ${ }^{[4]}$

However, high sugar levels are associated with increased health problems including obesity and chronic disease. Therefore, ingredients which can lead to calorie reduction such as sugar replacers can be considered as instrumental in weight control strategies. Stevianna (product code ST001 SE supplied by Stevianna NZ) was used for our study, as it incorporates rebaudioside A $(98 \%$ steviol glycoside; 1\%) with erythritol (99\%). Rebaudioside A is extracted from stevia, has broad health-promoting properties for blood glucose and insulin levels. ${ }^{[6]}$ Erythritol is a sugar alcohol which is absorbed very slowly and provides reduced calorie sweetening. ${ }^{[7]}$

Inulin is a dietary fibre ${ }^{[8]}$ and has prebiotic properties, hence it is a nutraceutical ingredient that is extensively used in the food products. ${ }^{\left[{ }^{9]}\right.}$ Inulin is a carbohydrate of the fructan family with $\beta$ $(2-1)$ linked fructose residues and a terminal glucose residue. ${ }^{[10]}$ Short-chain inulin, can be used as a sugar substitute in bakery products $^{[11]}$ and is useful in the treatment of obesity and diabetes. ${ }^{[12]}$

Several researchers have reported about the importance of the formulation and processing parameters on the functional properties of sugar substitutes. Partial replacement of sucrose 
with erythritol in a baked product resulted in positive influence on physical quality characteristics. ${ }^{[13-15]}$ Manisha et al. ${ }^{[16]}$ conducted research using a mixture of stevioside and liquid sorbitol in reduced sugar cakes and obtained effects on the rheological, microstructural, and quality characteristics of the modified cakes.

Inulin is typical sucrose or fat replacers in baked goods and their properties have been studied along with other fibre components, by many researchers. ${ }^{[17-20]}$ The rheological properties and the sensory quality of a product will not be affected strongly due to the neutral or slightly sweet taste and the limited effect on viscosity of this ingredient.

Apart from above sugar replacers functional role in lowcalorie baked products, they have also been used in the bakery products for the control over blood glucose and for the control of body weight or energy balance. ${ }^{[21-23]}$ Furthermore, previous work has found that the predicted glycaemic response was reduced when sugar was replaced with inulin or Stevianna in muffins compared to full-sugar samples. ${ }^{[24]}$

The aim of this study was to explore whether inulin and Stevianna could replace sugar in muffin batter and whether the RVA could be a tool for evaluating muffin chemical properties in relation to our previous paper. ${ }^{[25]}$ Sugar was replaced by different levels of each substitute in two kinds of muffin recipe. The effect of sugar replacers on starch gelatinization and batter viscosity during baking were separately studied through DSC and RVA assays, as well as in vitro starch digestibility of the batter was investigated.

\section{Experimental Section}

\subsection{Raw Materials}

The standard formulation was Wheat flour (Medal Premium baker flour, Champion, Auckland, New Zealand), white sugar (Chelsea, Auckland, New Zealand), baking powder (Edmonds, Auckland, New Zealand), iodized table salt (Cerebos, Auckland, New Zealand), skim milk powder (Pams, Auckland, New Zealand), canola oil (Pams, Auckland, New Zealand), and fresh whole egg (obtained from the local New World supermarket, Food Stuffs, Christchurch, New Zealand). Inulin Frutafit IQ, an inulin with DP 5-7 and sweetness of $10 \%$ compared to $100 \%$ sucrose (Sensus, Amsterdam, the Netherlands). Stevianna (product code ST001_SE; Stevianna, Auckland, New Zealand), Stevianna utilizes organic Reb-A 98\% stevia as the main sugar substitute along with erythritol as bulking agent. Cocoa powder (Cadbury, Dunedin, New Zealand) and vanilla (Hansells, Auckland, Australia) were used in Recipe 2.

\subsection{Preparation of Muffin Batter}

Two muffin batter recipes were utilized as described in previous research by Gao et al. ${ }^{[24,25]}$

Recipe $1^{[25]}$ muffin batter contained $69.2 \mathrm{~g}$ sugar, $8.7 \mathrm{~g}$ skim milk powder, $5.8 \mathrm{~g}$ baking powder, $1.4 \mathrm{~g}$ salt, $34.6 \mathrm{~g}$ liquid whole egg, $57.6 \mathrm{~g}$ oil, $57.6 \mathrm{~g}$ water, and $115.3 \mathrm{~g}$ wheat flour. Addition of Stevianna or inulin was a used to replace sugar at $25 \%, 50 \%, 75 \%$ and $100 \%$. All liquid ingredients were mixed for $60 \mathrm{~s}(10 \mathrm{~s}$ at speed $4 ; 50 \mathrm{~s}$ at speed 8$)$. Then, all the dry ingredients were added and mixed with the mixer for another $120 \mathrm{~s}(10 \mathrm{~s}$ at speed 2; $110 \mathrm{~s}$ at speed 8).

The ingredients used in the preparation of the Recipe 2 paper $^{[24]}$ muffin batter were $138.4 \mathrm{~g}$ wheat flour, $92.2 \mathrm{~g}$ sugar, $8.7 \mathrm{~g}$ skim milk powder, $6.5 \mathrm{~g}$ baking powder, $1.4 \mathrm{~g}$ salt, and $34.6 \mathrm{~g}$ liquid whole egg, $77.6 \mathrm{~g}$ oil and $97.6 \mathrm{~g}$ water. Stevianna was used as a sugar replacer at $50 \%$ and $100 \%$. Additional batters were made by adding $23.1 \mathrm{~g}$ cocoa powder or $3 \mathrm{~g}$ vanilla to recipe 2 muffin batter. Liquid ingredients were mixed for $60 \mathrm{~s}(10 \mathrm{~s}$ at speed $4 ; 50 \mathrm{~s}$ at speed 8$)$. Then, dry ingredients were added into the premixed liquid and mixed for $10 \mathrm{~s}$ at speed 2 then $170 \mathrm{~s}$ at speed 8.

\subsection{Pasting Properties of Batter}

A RVA (Super 4; Newport Scientific, Warriwold, Australia) was used to determine the viscosity properties of the muffins batter by a personal computer running ThermoCline for Windows $v 3$ (TCW3) software. The RVA studies were carried out using $20 \mathrm{~g}$ of batter sample in an aluminium canister. The temperature profile started with a holding step at $25^{\circ} \mathrm{C}$ for $5 \mathrm{~min}$, followed by a linear temperature increase from 25 to $95^{\circ} \mathrm{C}$ at $2{ }^{\circ} \mathrm{Cmin}^{-1}$ and a holding step of $25 \mathrm{~min}$ at $95^{\circ} \mathrm{C}$. The paddle speed was $75 \mathrm{rpm}$ (rotations per $\mathrm{min}$ ). The TCW3 software continuously recorded the viscosity and calculated the peak viscosity and final viscosity.

\subsection{Differential Scanning Calorimetry}

DSC was performed using a DSC 8000 (PerkinElmer, Waltham, USA) to investigate the thermal parameters of muffin batter and to evaluate the changes in starch at the molecular level during baking. Batter $(3 \mathrm{mg}$ ) was mixed with distilled water, to a total weight of $10 \mathrm{mg}$, in a gold DSC pan and then left to equilibrate for $2 \mathrm{~h}$ prior to the testing. The samples were heated from 0 to $110^{\circ} \mathrm{C}$ at $10^{\circ} \mathrm{C} \mathrm{min}^{-1}$, together with an empty reference pan, and indium was used for calibration. The thermal parameters associated with the gelatinization process, onset temperature $\left(\mathrm{T}_{\text {onset }}\right)$, peak temperature $\left(\mathrm{T}_{\text {peak }}\right)$, end temperature $\left(\mathrm{T}_{\text {endset }}\right)$, and the change of enthalpy $(\Delta \mathrm{H})$, were measured by heating the crystalline material at $10^{\circ} \mathrm{C} \mathrm{min}^{-1}$ rate to a temperature.

\subsection{In vitro Predictive Glycaemic Response Digestion Analysis}

In vitro digestion was conducted on all of the RVA gels to determine the predictive glycaemic response in the "cooked" muffin mixture.

The procedure for measuring the breakdown of carbohydrates to sugars follows that reported by. ${ }^{[25]}$ A $3.5 \mathrm{~g}$ sample of "RVA cooked" mix was used to determine the predictive glycaemic response. The procedure used pancreatin to digest the food and the amount of reducing sugars released (RSR) over a $120 \mathrm{~min}$ digestion process was determined. Samples were incubated at $37^{\circ} \mathrm{C}$ with constant stirring, triplicate $1 \mathrm{~mL}$ aliquots were withdrawn at $0,20,60,120 \mathrm{~min}$ and added to $4 \mathrm{~mL}$ absolute ethanol. ${ }^{[26]}$ Reducing sugar content was analyzed by 
dinitrosalicyclic (DNS) colorimetry, and area under the curve (AUC) was calculated by dividing the graph into trapezoids as described elsewhere. ${ }^{[27]}$

\subsection{Statistical Analysis}

Each analysis was conducted in triplicate. Analysis of variance (one-way ANOVA) was performed on the data, and Tukey's comparison test $(p<0.05)$ was used to determine the significance. These analyses were performed using Minitab (Minitab Pty Ltd, Sydney, Australia).

\section{Results and Discussion}

\subsection{Pasting Properties of the Batter}

Pasting properties of muffin batter were measured using an RVA which measures changes in viscosity during heating from 25 to $95^{\circ} \mathrm{C}$.

Table 1 shows peak and final viscosity for muffin batters. There were no significant differences between the control and samples containing Stevianna for either peak viscosity or final viscosity for recipe 1 . In this regard, the Stevianna was successful in mimicking the effect of sucrose on the viscosity properties of batter during heating. The sucrose-induced delay in starch gelatinization has been demonstrated to be a result of antiplasticization by sugar-water co-solvents as compared to water alone. ${ }^{[16]}$ Struck et al. ${ }^{[28]}$ reported that intermolecular interactions of sucrose with starch chains in the amorphous regions of the starch granule led to the stabilization of those regions. Therefore, Stevianna appears to have simulated the effect of sucrose as the viscosity values were similar to the control sample. This indicates delayed starch gelatinization and thermosetting thus time was allowed for appropriate air and vapor expansion during baking.

The peak and final viscosity of batter containing inulin increased significantly compared to the control apart from $25 \%$ replacement, and each increased level of replacement had significantly higher viscosity. Batter viscosity increase might be attributed to the high water-holding capacity of the fibre and a tendency to form a networked gel structure. ${ }^{[22]}$ Inulin is highly hydrophilic resulting in a decrease in water availability swelling starch granules, thus reducing the formation of structural hydrocolloids in the batter. ${ }^{[11]}$ A similar relationship was

Table 1. Pasting properties of batter enriched sugar replacers as measured by the rapid visco analyzer (RVA) and in vitro starch digestion profile in low-sugar batters.

\begin{tabular}{|c|c|c|c|}
\hline \multirow{2}{*}{$\begin{array}{l}\text { Sample } \\
\text { Recipe } 1\end{array}$} & \multicolumn{2}{|c|}{ RVA } & \multirow{2}{*}{$\frac{\text { In vitro starch digestibility }}{\text { Total AUC }\left(\mathrm{mg} \mathrm{g}^{-1}\right)}$} \\
\hline & Peak viscosity (cP) & Final viscosity $(\mathrm{cP})$ & \\
\hline Control & $10559 \pm 274^{d}$ & $5669 \pm 127^{c}$ & $456.52 \pm 9.16^{\mathrm{a}}$ \\
\hline $25 \%$ Stevianna & $10371 \pm 343^{d}$ & $5517 \pm 209^{c}$ & $420.16 \pm 7.11^{\mathrm{a}}$ \\
\hline $50 \%$ Stevianna & $10393 \pm 242^{d}$ & $5555 \pm 333^{c}$ & $339.13 \pm 9.05^{b c}$ \\
\hline 75\% Stevianna & $10557 \pm 350^{d}$ & $5587 \pm 262^{c}$ & $316.99 \pm 8.27^{\mathrm{cd}}$ \\
\hline $100 \%$ Stevianna & $10471 \pm 525^{d}$ & $5379 \pm 323 c$ & $237.27 \pm 21.90^{\mathrm{e}}$ \\
\hline $25 \%$ Inulin & $11329 \pm 368^{d}$ & $5518 \pm 412^{c}$ & $427.74 \pm 17.34^{\mathrm{a}}$ \\
\hline $50 \%$ Inulin & $13907 \pm 242^{c}$ & $18810 \pm 389^{\mathrm{b}}$ & $364.36 \pm 14.69^{\mathrm{b}}$ \\
\hline $75 \%$ Inulin & $22306 \pm 307^{b}$ & $20499 \pm 424^{a}$ & $336.27 \pm 8.29^{b c}$ \\
\hline $100 \%$ Inulin & $31697 \pm 525^{\mathrm{a}}$ & $20424 \pm 202^{\mathrm{a}}$ & $284.34 \pm 13.70^{d}$ \\
\hline \multicolumn{4}{|l|}{ Recipe 2} \\
\hline Control & $5747 \pm 309^{c}$ & $5609.7 \pm 45.2^{\mathrm{ab}}$ & $431.27 \pm 19.24^{a}$ \\
\hline Vanilla & $5712 \pm 109.3^{c}$ & $5787 \pm 296^{\mathrm{ab}}$ & $413.16 \pm 8.85^{\mathrm{ab}}$ \\
\hline Cocoa powder & $7492 \pm 232^{\mathrm{a}}$ & $6373 \pm 186^{a}$ & $374.47 \pm 16.20^{c}$ \\
\hline $\mathrm{CP}+$ Vanilla & $7447 \pm 364^{a}$ & $6356 \pm 541^{\mathrm{a}}$ & $386.86 \pm 13.27^{\mathrm{bc}}$ \\
\hline $50 \%$ Stevianna & $4479 \pm 104^{d}$ & $4560 \pm 222^{c}$ & $287.14 \pm 6.72^{d}$ \\
\hline $50 S+V$ & $4361 \pm 218^{d}$ & $4563 \pm 358^{c}$ & $285.92 \pm 10.13^{d}$ \\
\hline $50 \mathrm{~S}+\mathrm{CP}$ & $6574 \pm 176^{\mathrm{b}}$ & $6157 \pm 223^{\mathrm{ab}}$ & $273.53 \pm 4.96^{\mathrm{d}}$ \\
\hline $50 S+C P+V$ & $6655 \pm 246^{\mathrm{b}}$ & $6106 \pm 403^{\mathrm{ab}}$ & $266.99 \pm 9.28^{d}$ \\
\hline $100 \%$ Stevianna & $4847 \pm 329^{d}$ & $3303 \pm 224^{d}$ & $213.49 \pm 3.69^{\mathrm{e}}$ \\
\hline $100 S+V$ & $4601 \pm 448^{d}$ & $3503 \pm 223^{b c}$ & $211.48 \pm 7.15^{\mathrm{e}}$ \\
\hline $100 S+C P$ & $6587.3 \pm 149^{\mathrm{b}}$ & $5408 \pm 368^{b c}$ & $187.34 \pm 6.88^{\mathrm{e}}$ \\
\hline $100 S+C P+V$ & $6569 \pm 172^{b}$ & $5409 \pm 382^{b c}$ & $188.17 \pm 10.41^{\mathrm{e}}$ \\
\hline
\end{tabular}

$50 \%$ Stevianna + Vanilla $(50 \mathrm{~S}+\mathrm{V}) ; 50 \%$ Stevianna + Cocoa $(50 \mathrm{~S}+\mathrm{CP}) ; 50 \%$ Stevianna + Cocoa + Vanilla $(50 \mathrm{~S}+\mathrm{CP}+\mathrm{V}) ; 100 \%$ Stevianna + Vanilla $(100 \mathrm{~S}+\mathrm{V}) ; 100 \%$ Stevianna + Cocoa $(100 \mathrm{~S}+\mathrm{CP}) ; 100 \%$ Stevianna + Cococa + Vanilla $(100 \mathrm{~S}+\mathrm{CP}+\mathrm{V})$. All measurements are mean values $\pm \mathrm{SD}$ of triplicate determinations. Means in the same column with different letters are significantly different $(p<0.05)$. 
reported by Zahn et al., ${ }^{[29]}$ batter flowability increased with an increasing amount of inulin as a fat replacement. Batter flowability is significantly related to the volume of the final product, as Frutafit IQ inulin is a prefabricated gel, the reduction of bakery product volume was attributed to excessive batter consistency limiting the batter expansion in the fat-free product recipe Zahn et al. ${ }^{[29]}$ The highest viscosity was observed with inulin replacing $100 \%$ of sugar as the presence of inulin inhibited the hydration of the starch granules by bonding to the available water and thus also reduced aeration of the cake batter. $^{[30]}$ Inulin is capable of forming entangled networks with other food components when mixed with water and forming a highly viscous polymer. Final viscosity is related to the formation of viscoelastic gel. The $25 \%$ inulin replacement of sugar did not cause a significant increase of viscosity during heating in comparison to control sample, which was probably due to its low amount of substitution. This result agrees with Gularte et al. ${ }^{[22]}$ who reported the batter viscosity displayed no significant differences when added $20 \%$ inulin in layer cake.

Four batters were made without Stevianna using Recipe 2, (original, with vanilla, with cocoa powder, and with cocoa powder and vanilla) replacement of sugar with Stevianna at $50 \%$ or $100 \%$ in each of these batters resulted in a significant reduction in peak viscosity. Although it is noted that the two batters that included cocoa powder always had a significantly higher peak viscosity that the comparative batters without cocoa powder. The final viscosity of the four batters was significantly reduced when sucrose was replaced with $100 \%$ Stevianna. The final viscosity of batters without cocoa powder were also significantly reduced when sucrose was replaced with 50\% Stevianna. This indicates that Stevianna had an effect on the viscosity of Recipe 2 whereas it did not in Recipe 1 when compared to control samples (Recipe 1). This difference could be attributed to the interactions between the recipe components and the ratio of the batter constituents of flour, sugar, egg, water, and oil. Manisha et al. ${ }^{[16]}$ reported that decreased batter stability, of sugar-free cake, during heating led to a decrease in expansion. It was found that the inclusion of sorbitol and stevioside affected the viscosity of the starch, as they interrupted the usual starch protein interactions that occur during gelatinization which then caused changes in the thermosetting mechanism

Batter viscosity during baking affects the retention of air and leavening gases. ${ }^{[31]}$ The peak viscosity increased significantly with the addition of cocoa powder (Table 1 ). Do et al. ${ }^{[32]}$ found a higher apparent viscosity when chocolate was formulated with standard cocoa power. The cocoa particles swelled and led to a perception of coarse texture in water-based applications. ${ }^{\text {[3] }}$ Martínez-Cervera et al. ${ }^{[34]}$ reported that using cocoa as a fat replacer in muffins profoundly modified the batter viscosity, possibly due to cocoa powder interfering with leavening agents, affecting the capacity of the batter to retain air bubbles during beating and heating. ${ }^{[33]}$

\subsection{Effect of Starch Gelatinization on Batter}

The DSC results are shown in Table 2, these results are similar to that expected when considering from values of batter viscosity during baking (Table 1).
All batters with Stevianna replacement, both recipe 1 and 2 showed no significant differences to the control in any of the measured parameters $\left(\mathrm{T}_{\text {onset }}, \mathrm{T}_{\text {peak }}, \mathrm{T}_{\text {endset }}\right)$. The enthalpy of gelatinization $(\Delta \mathrm{H})$ was not observed to be significantly different between samples. Martínez-Cervera et al. ${ }^{[35]}$ suggested polyols such as sorbitol, maltitol, and erythritol, as total sucrose replacers in muffins, due to the starch gelatinization temperature being very similar when using sucrose or polyols. Use of the polyols, sorbitol and lactitol, as sugar substitutes in cake batter was found to have no significant influence on the gelatinization enthalpies by Psimouli and Oreopoulou. ${ }^{[4]}$

The addition of cocoa powder and vanilla had no significant effect on $\mathrm{T}_{\text {onset }}, \mathrm{T}_{\text {peak }}$, $\mathrm{T}_{\text {endset}}$, or the enthalpy of gelatinization $(\Delta \mathrm{H})$ compared to the control. Although the RVA analysis of the gelatinizing batter properties illustrated that there were significant differences between control sample and those including cocoa powder (Table 1), this observation was not clear in the DSC measurement (Table 2). Such as a result illustrates that the DSC and RVA protocols examine different physiological properties of starch based systems and are therefore not directly comparable.

Replacing $100 \%$ sugar with inulin, significantly increased $\mathrm{T}_{\text {onset }}, \mathrm{T}_{\text {peak }}$, and $\mathrm{T}_{\text {endset}}$, it was the only sample to show significant difference to the control at the measured parameters $\left(\mathrm{T}_{\text {onset }}, \mathrm{T}_{\text {peak }}, \mathrm{T}_{\text {endset }}\right)$. However, replacement of $75 \%$ and $100 \%$ sugar with inulin showed a significant reduction in the enthalpy of gelatinization $(\Delta \mathrm{H})$. Replacing the sugar with inulin caused the crystalline regions of starch to become more stable leading to higher $\mathrm{T}_{\text {onset }}, \mathrm{T}_{\text {peak }}$, and $\mathrm{T}_{\text {endset }}$ values. These results are consistent with research that shows the inclusion of inulin leads to an increase in gelatinization temperature in gluten-free dough. ${ }^{[36]}$ This may be because thermal transition temperatures are higher after inulin incorporation, as it forms a gel structure. Another factor could be concerned with inulin decreasing the water activity and hence limit starch swelling and gelatinization events. ${ }^{[8]}$ Psimouli and Oreopoulou ${ }^{[37]}$ have reported that the presence of inulin profoundly modified starch gelatinization in cake batter, due to its ability to bind water and act as a stabilizer of the amorphous region in the starch granule. Aravind et al., ${ }^{[38]}$ also observed that inulin in starch-water systems raised starch gelatinization temperature. The reduction in the enthalpy of gelatinization $(\Delta \mathrm{H})$ is likely to be related directly to the concentration of inulin within the system. Tudorică et al. ${ }^{[8]}$ indicated that the enthalpy of a system is an indicator of the amount of starch gelatinization within a starch base and should be related to the gelatinization temperature of the starch within the system. This can be explained by pockets of higher fibre concentrations where cross-linked gums form resulting in less encapsulation of individual starch granules. ${ }^{[8]}$

\subsection{In vitro Predictive Glycaemic Response for Batter}

For recipe 1 the amount of reducing sugar present at time zero was significantly lower in all samples containing Stevianna and inulin when compared with full sugar samples this would be expected due to there being less sugar in the recipe. The amount of RSR at 20 min was reduced with the replacement of sugar with $50 \%, 75 \%$, and $100 \%$ inulin or Stevianna (Figure 1). A similar 
Table 2. Gelatinization parameters (DSC measurements) of batter samples showing the effect of sugar replacer addition with/without cocoa powder and/or vanilla.

\begin{tabular}{|c|c|c|c|c|}
\hline Sample & DSC & & & \\
\hline Recipe 1 & Tonset $\left({ }^{\circ} \mathrm{C}\right)$ & Tpeak $\left({ }^{\circ} \mathrm{C}\right)$ & Tendset $\left({ }^{\circ} \mathrm{C}\right)$ & Enthalpy (DeltaH, $\left.\mathrm{Jg}^{-1}\right)$ \\
\hline Control & $66.27 \pm 0.90^{\mathrm{bc}}$ & $69.82 \pm 1.57^{\mathrm{b}}$ & $75.44 \pm 1.43^{\mathrm{bc}}$ & $1.59 \pm 0.09^{\mathrm{a}}$ \\
\hline 25\% Stevianna & $65.41 \pm 1.94^{c}$ & $69.87 \pm 1.79^{b}$ & $73.79 \pm 0.80^{c}$ & $1.53 \pm 0.08^{\mathrm{a}}$ \\
\hline $50 \%$ Stevianna & $65.78 \pm 1.76^{b c}$ & $70.93 \pm 1.08^{\mathrm{ab}}$ & $75.61 \pm 0.79^{b c}$ & $1.47 \pm 0.05^{\mathrm{a}}$ \\
\hline 75\% Stevianna & $66.31 \pm 2.02^{b c}$ & $70.49 \pm 2.06^{\mathrm{ab}}$ & $76.27 \pm 1.01^{b c}$ & $1.53 \pm 0.16^{\mathrm{a}}$ \\
\hline $100 \%$ Stevianna & $67.42 \pm 3.98^{\mathrm{abc}}$ & $69.90 \pm 3.90^{\mathrm{b}}$ & $73.34 \pm 1.90^{c}$ & $1.45 \pm 0.09^{\mathrm{a}}$ \\
\hline $25 \%$ Inulin & $65.72 \pm 0.69^{b c}$ & $70.55 \pm 0.49^{\mathrm{ab}}$ & $75.03 \pm 0.82^{b c}$ & $1.56 \pm 0.08^{\mathrm{a}}$ \\
\hline $50 \%$ Inulin & $65.08 \pm 1.73^{c}$ & $70.67 \pm 0.83^{\mathrm{ab}}$ & $75.19 \pm 1.26^{\mathrm{bc}}$ & $1.47 \pm 0.08^{\mathrm{a}}$ \\
\hline $75 \%$ Inulin & $70.99 \pm 0.92^{\mathrm{ab}}$ & $73.49 \pm 0.97^{\mathrm{ab}}$ & $77.74 \pm 0.48^{\mathrm{ab}}$ & $1.06 \pm 0.03^{b}$ \\
\hline $100 \%$ Inulin & $72.56 \pm 0.67^{\mathrm{a}}$ & $75.42 \pm 0.03^{\mathrm{a}}$ & $79.39 \pm 0.24^{\mathrm{a}}$ & $0.49 \pm 0.05^{c}$ \\
\hline \multicolumn{5}{|l|}{ Recipe 2} \\
\hline Control & $66.43 \pm 0.81^{\mathrm{a}}$ & $70.24 \pm 1.36^{\mathrm{a}}$ & $74.80 \pm 1.03^{\mathrm{a}}$ & $1.57 \pm 0.06^{\mathrm{a}}$ \\
\hline Vanilla & $65.58 \pm 1.38^{\mathrm{a}}$ & $71.64 \pm 0.70^{\mathrm{a}}$ & $74.85 \pm 0.73^{\mathrm{a}}$ & $1.60 \pm 0.02^{\mathrm{a}}$ \\
\hline Cocoa powder & $66.06 \pm 2.64^{\mathrm{a}}$ & $69.08 \pm 2.76^{\mathrm{a}}$ & $74.39 \pm 1.89^{\mathrm{a}}$ & $1.57 \pm 0.33^{\mathrm{a}}$ \\
\hline $\mathrm{CP}+$ Vanilla & $65.80 \pm 1.84^{\mathrm{a}}$ & $72.82 \pm 2.05^{\mathrm{a}}$ & $76.13 \pm 0.41^{\mathrm{a}}$ & $1.55 \pm 0.45^{\mathrm{a}}$ \\
\hline $50 \%$ Stevianna & $66.97 \pm 1.04^{\mathrm{a}}$ & $71.74 \pm 0.89^{\mathrm{a}}$ & $74.36 \pm 0.90^{\mathrm{a}}$ & $1.57 \pm 0.25^{\mathrm{a}}$ \\
\hline $50 S+V$ & $66.77 \pm 4.00^{\mathrm{a}}$ & $71.52 \pm 3.56^{\mathrm{a}}$ & $75.35 \pm 2.84^{\mathrm{a}}$ & $1.50 \pm 0.25^{\mathrm{a}}$ \\
\hline $50 \mathrm{~S}+\mathrm{CP}$ & $65.61 \pm 2.54^{\mathrm{a}}$ & $71.30 \pm 1.65^{\mathrm{a}}$ & $75.93 \pm 0.37^{\mathrm{a}}$ & $1.55 \pm 0.05^{\mathrm{a}}$ \\
\hline $50 S+C P+V$ & $65.80 \pm 2.44^{\mathrm{a}}$ & $70.81 \pm 0.95^{\mathrm{a}}$ & $74.91 \pm 2.44^{\mathrm{a}}$ & $1.41 \pm 0.39^{\mathrm{a}}$ \\
\hline $100 \%$ Stevianna & $66.59 \pm 1.66^{\mathrm{a}}$ & $70.50 \pm 1.65^{\mathrm{a}}$ & $74.66 \pm 1.81^{\mathrm{a}}$ & $1.56 \pm 0.11^{\mathrm{a}}$ \\
\hline $100 S+V$ & $65.27 \pm 0.92^{\mathrm{a}}$ & $70.47 \pm 0.81^{\mathrm{a}}$ & $75.29 \pm 1.32^{\mathrm{a}}$ & $1.51 \pm 0.14^{\mathrm{a}}$ \\
\hline $100 S+C P$ & $65.81 \pm 2.18^{\mathrm{a}}$ & $70.12 \pm 1.17^{\mathrm{a}}$ & $74.93 \pm 1.56^{\mathrm{a}}$ & $1.52 \pm 0.17^{\mathrm{a}}$ \\
\hline $100 S+C P+V$ & $65.98 \pm 2.65^{\mathrm{a}}$ & $70.85 \pm 0.66^{\mathrm{a}}$ & $75.25 \pm 1.20^{\mathrm{a}}$ & $1.52 \pm 0.11^{\mathrm{a}}$ \\
\hline
\end{tabular}

$50 \%$ Stevianna + Vanilla $(50 \mathrm{~S}+\mathrm{V}) ; 50 \%$ Stevianna + Cocoa $(50 \mathrm{~S}+\mathrm{CP}) ; 50 \%$ Stevianna + Cocoa + Vanilla $(50 \mathrm{~S}+\mathrm{CP}+\mathrm{V}) ; 100 \%$ Stevianna + Vanilla $(100 \mathrm{~S}+\mathrm{V}) ; 100 \%$ Stevianna + Cocoa $(100 \mathrm{~S}+\mathrm{CP}) ; 100 \%$ Stevianna + Cococa + Vanilla $(100 \mathrm{~S}+\mathrm{CP}+\mathrm{V})$. All measurements are mean values $\pm \mathrm{SD}$ of triplicate determinations. Means in the same column with different letters are significantly different $(p<0.05)$.

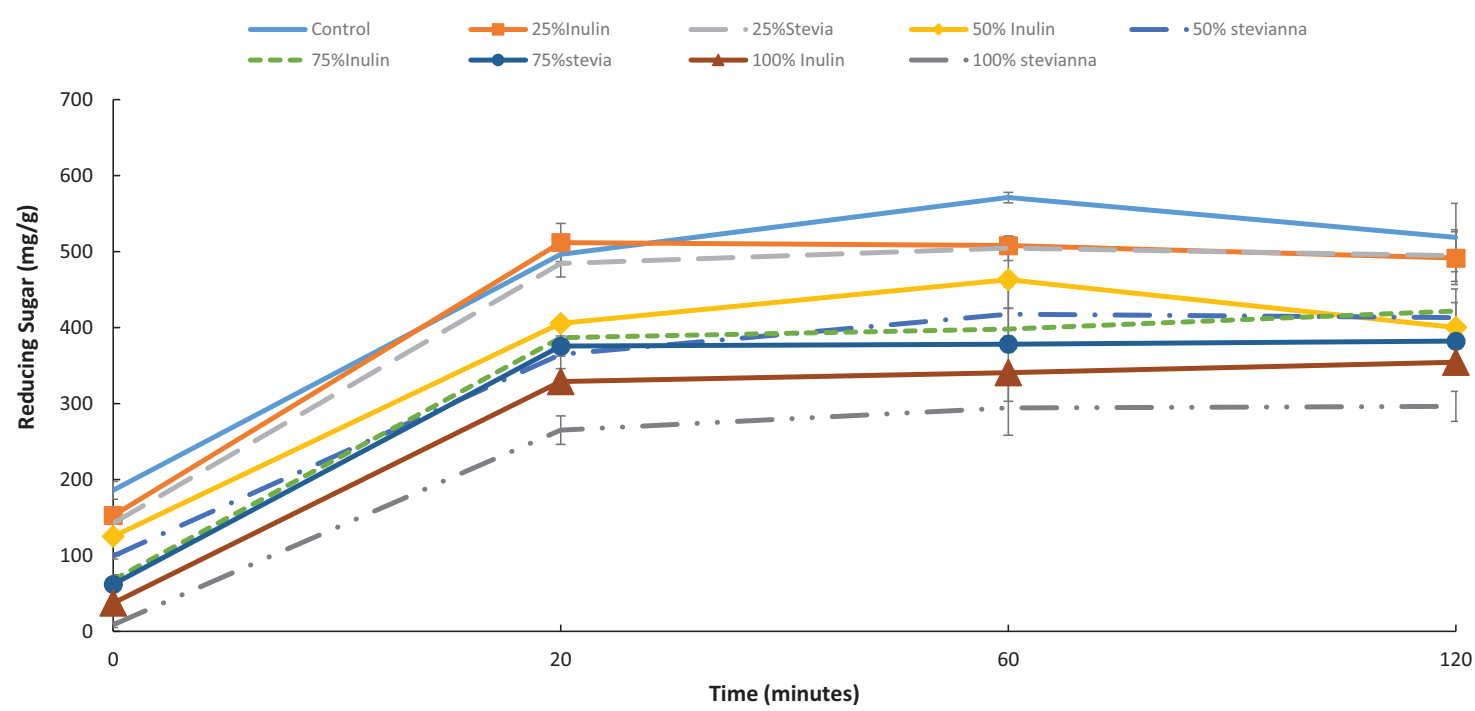

Figure 1. Amount of reducing sugars released during in vitro digestion for Recipe 1. A total of $50 \%$ Stevianna + Vanilla $(50 S+V)$; $50 \%$ Stevianna + Cocoa $(50 S+C P) ; 50 \%$ Stevianna + Cocoa + Vanilla $(50 S+C P+V) ; 100 \%$ Stevianna + Vanilla $(100 S+V) ; 100 \%$ Stevianna + Cocoa $(100 S+C P) ; 100 \%$ Stevianna + Cococa + Vanilla $(100 S+C P+V)$. 


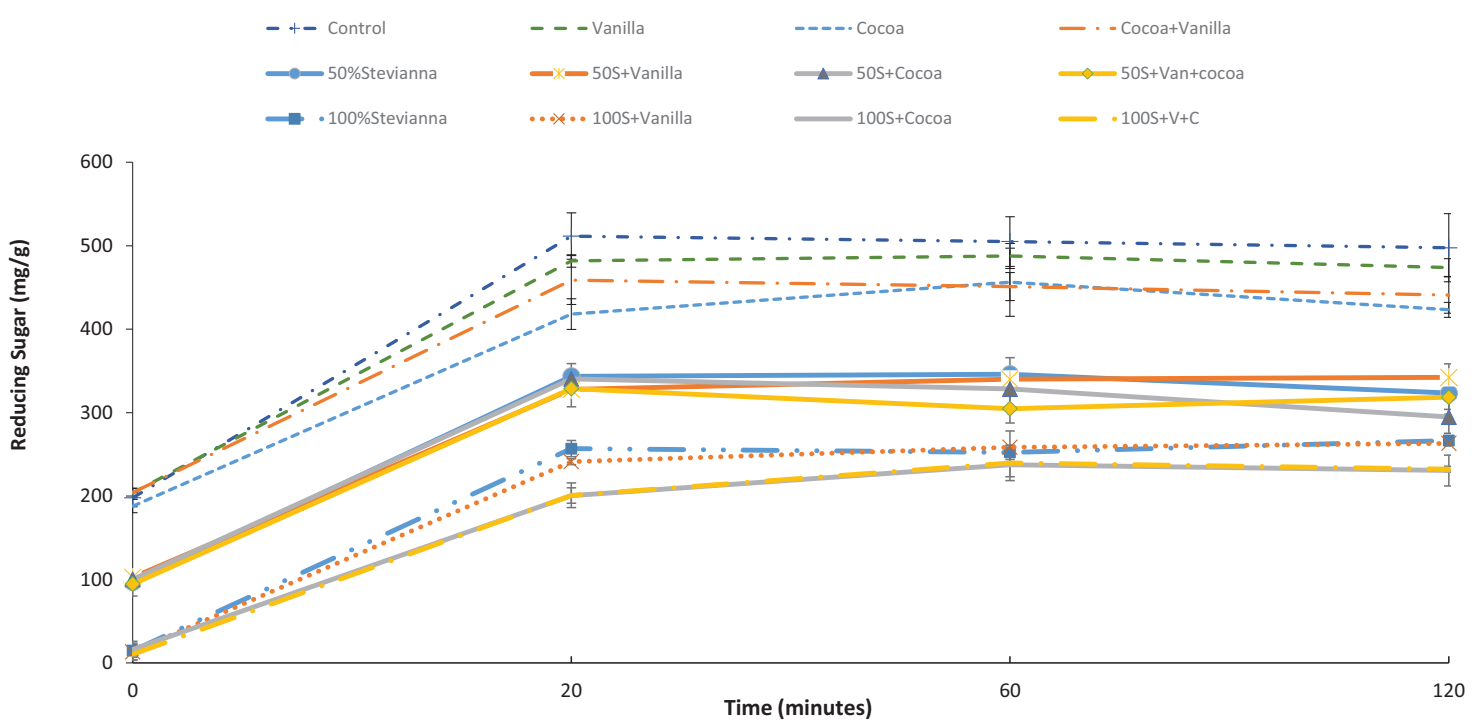

Figure 2. Amount of reducing sugars released during in vitro digestion for Recipe 2. A total of $50 \%$ Stevianna $+V a n i l l a ~(50 S+V)$; $50 \%$ Stevianna + Cocoa (50S + CP); 50\% Stevianna + Cocoa + Vanilla (50S + CP + V); 100\% Stevianna + Vanilla (100S + V); 100\% Stevianna + Cocoa $(100 S+C P) ; 100 \%$ Stevianna + Cococa + Vanilla $(100 S+C P+V)$.

pattern was observed at 60 and $120 \mathrm{~min}$, the reducing sugar release in samples with of more than $50 \%$ sugar replacer samples were significantly lower than control. There was a significant decrease in AUC values when inulin or Stevianna levels were used to replace sugar at $50 \%, 75 \%$, or $100 \%$.

These results are consistent with data obtained in previous research, ${ }^{[25]}$ indicating the inclusion of Stevianna or inulin in baked muffins can significantly reduce the predicted glycaemic response. The reduction in glycaemic response level in inulin replaced muffin products has been thought to be related to the added viscosity that inulin provides during digestion, resulting in the entrapment of starch granules within a viscous fibrestarch network. For instance, Brennan et al. ${ }^{[39]}$ illustrated a similar occurrence in fibre enriched breakfast cereals, where the postprandial glucose impact of these foods compared was reduced compared with non-fibre cereal products. In addition, Foschia et al. ${ }^{[40]}$ found that starch gelatinization properties has effect on starch digestion and reducing sugar release. In this study, low level inulin sample $(<50 \%)$ did not cause significantly viscosity differences. However, the gelatinization temperatures of inulin sample indicate that the inulin had a protective effect on the starch granules. Bae et al. ${ }^{[30]}$ also found that the addition of inulin to cake, restricted starch hydrolysis, hence lowering reducing sugar release under in vitro conditions. Tudorică et al. ${ }^{[8]}$ observed a similar result in pasta, it was found that inulin becomes incorporated into the structure of pasta, resulting in a significantly reduced value of glucose release with the inclusion of inulin.

Recipe 2 (Figure 2) which only used Stevianna to replace sugar showed similar results to the Stevianna replacement in Recipe 1 (Figure 1). Stevianna concentration had a significant effect on the AUC values $(p<0.05)$. However, the mechanism of action may be different to that of inulin as Stevianna is composed of rebaudioside A, for sweetness, and erythritol, as a filler, thus it has virtually no calorific value and probably does not interact with starch and water in the same was as inulin does, as noted by the viscosity results.

Other work has been carried out using stevia in ice cream and beverages that have shown a reduced postprandial glucose response when compared with a control. ${ }^{[41]}$ Stevia contains no glucose thus, stevia does not contribute to the available carbohydrate and glycaemic responses in food products thereby giving it very different functional properties to sucrose. Carakostas et al. ${ }^{[42]}$ studies provide further evidence that purified rebaudioside $\mathrm{A}$ has no effect on either blood pressure or glucose homeostasis for use in food and beverages.

The main component of Stevianna is erythritol. When erythitol has been used by other researchers as a sucrose replacement they have found that postprandial glucose and insulin levels were reduced. ${ }^{[23]}$ These results are due to the lack calorie and carbohydrate content of erythritol, thus there are no raising postprandial glycemic and insulin levels by oral ingestion in healthy human subjects. ${ }^{[14]}$

Batters with Stevianna that include cocoa powder and/or vanilla in Recipe 2, also appeared relatively lower RSR and AUC values (Figure 2 and Table 1) than the control batter, but no significant difference of Stevianna samples without cocoa powder and/or vanilla was observed. These results are consistent with previous report (unpublished) findings which showed the additions of vanilla and/or cocoa powder with baked muffin production did not lead to significant reduction of in vitro digestion values compared to the $50 \%$ and $100 \%$ Stevianna samples. However, the full-sucrose batter samples containing cocoa powder had significantly lower AUC values than the control (Table 1). This inconsistency may be since cocoa powder contains fibre components, which may interact with the starch and therefore reduce the potential glycaemic impacts.

In summary, the results of batter samples with sugar replacer are consistent with data obtained from baked muffin products (same recipe) by in vitro starch digestion, indicating that the 
baking process did not have an impact on the predictive glycaemic response. There are two main sugar replacers that could be critical in reducing the glycaemic response of muffin batter. The first one is that the inulin formed a matrix to encase starch granules, resulting in the limitation of starch swelling and gelatinization events and, consequently, the reduced potential for starch degradation and sugar liberation. ${ }^{[8]}$ The second event could be the Stevianna evaluated the lost calories value that provides no energy to the body and thus is not systemically metabolized nor fermented in the colon. ${ }^{[42]}$ Furthermore, stevioside has been reported by Manisha ${ }^{[16]}$ as having good stability under normal conditions of application, and no interaction between the individual low calorie sweeteners.

\section{Conclusions}

This study on muffin batters show that the results of pasting properties, starch gelatinization, and potential nutritional quality are intrinsically linked to the ability of different levels of sugar substitutes into batter systems.

The positive effect of Stevianna on Recipe 1 batter properties is associated with the fact that Stevianna, like sucrose, did not differ significantly from the full-sugar batter in viscosity during heating. However, the inclusion of Stevianna with/without cocoa powder in Recipe 2 batter products showed different effects on the pasting properties, suggesting interactions between ingredients which were not present in Recipe 1 . At the same time, the sugar replacement with inulin led to Recipe 1 batters with increased viscosity during heating, resulting in the waterbinding ability of inulin and forming a networked gel structure.

DSC analysis showed that the inclusion of inulin increased starch gelatinization temperature and decreased $\Delta \mathrm{H}$ in the Recipe 1 batters, whereas no significant differences were found with Stevianna addition in Recipe 1 and 2 batters. Therefore, it can be concluded that addition of inulin has significant effect on the starch gelatinization properties of muffin batters.

\section{Keywords}

batter system, differential scanning calorimetry, Inulin, in vitro starch digestion, Stevianna, viscosity

Received: November 29, 2017 Revised: March 7, 2018

Published online: June 12, 2018

[1] S. Chevallier, P. Colonna, G. Della Valle, D. Lourdin, J. Cereal Sci. 2000, 31, 241.

[2] E. Wilderjans, B. Pareyt, H. Goesaert, K. Brijs, J. A. Delcour, Food Chemistry 2008, 110, 909.

[3] J. W. Donovan, J. Sci. Food Agric. 1977, 28, 571.

[4] V. Psimouli, V. Oreopoulou, J. Sci. Food Agric. 2012, 92, 99.

[5] E. Wilderjans, A. Luyts, H. Goesaert, K. Brijs, J. Delcour, Food Chem. 2010, 120, 44.

[6] J.-C. Chang, M. Wu, I.-M. Liu, J.-T. Cheng, Horm. Metab. Res. 2005, 37,610 .
[7] D. Storey, A. Lee, F. Bornet, F. Brouns, Eur. J. Clin. Nutr. 2007, 61, 349.

[8] C. Tudorica, V. Kuri, C. Brennan, J. Agric. Food Chem. 2002, 50, 347.

[9] D. Meyer, S. Bayarri, A. Tárrega, E. Costell, Food Hydrocolloids 2011, $25,1881$.

[10] A. Giri, S. K. Kanawjia, Y. Khetra, Food Bioprocess Technol. 2014, 7, 1533.

[11] L. González-Tomás, J. Coll-Marqués, E. Costell, Food Hydrocolloids 2008, 22, 1372.

[12] K. Swennen, C. M. Courtin, J. A. Delcour, Crit. Rev. Food Sci. Nutr. 2006, 46, 459.

[13] S. D. Lin, C. F. Hwang, C. H. Yeh, J. Food Sci. 2003, 68, 2107.

[14] J. M. Grigor, C. S. Brennan, S. C. Hutchings, D. S. Rowlands, Int. J. Food Sci. Technol. 2016, 51, 3.

[15] N. M. M., Alencar, E. C. de Morais, C. J. Steel, H. M. A. Bolini, Int. J. Food Sci. Technol. 2017, 52, 872.

[16] G. Manisha, C. Soumya, D. Indrani, Food Hydrocolloids 2012, 29, 363.

[17] C. O'brien, A. Mueller, A. Scannell, E. Arendt, J. Food Eng. 2003, 56, 265.

[18] S. Karp, J. Wyrwisz, M. A. Kurek, A. Wierzbicka, Int. J. Food Sci. Technol. 2017, 52, 944.

[19] B. Herranz, W. Canet, M. J. Jiménez, R. Fuentes, M. D. Alvarez, Int. J. Food Sci. Technol. 2016, 51, 1087.

[20] S. Zahn, A. Forker, L. Krügel, H. Rohm, LWT-Food Sci. Technol. 2013, 50, 695.

[21] S. Gregersen, P. B. Jeppesen, J. J. Holst, K. Hermansen, Metabolism. 2004, 53, 73.

[22] M. A. Gularte, E. de la Hera, M. Gómez, C. M. Rosell, LWT-Food Sci. Technol. 2012, 48, 209.

[23] S. D. Lin, C. C. Lee, J. L. Mau, L. Y. Lin, S. Y. Chiou, J. Food Qual. 2010, 33, 14.

[24] J. Gao, M. A. Brennan, S. L. Mason, C. S. Brennan, J. Food Qual. 2017, 2017.

[25] J. Gao, M. A. Brennan, S. L. Mason, C. S. Brennan, Int. J. Food Sci. Technol. 2016, 51, 1979.

[26] J. W. Woolnough, A. R. Bird, J. A. Monro, C. S. Brennan, Int. J. Mol. Sci. 2010, 11, 2780.

[27] J. Matthews, D. G. Altman, M. Campbell, P. Royston, BMJ 1990, 300, 230.

[28] S. Struck, L. Gundel, S. Zahn, H. Rohm, LWT-Food Sci. Technol. 2016, $65,32$.

[29] S. Zahn, F. Pepke, H. Rohm, Int. J. Food Sci. Technol. 2010, 45, 2531.

[30] I. Y. Bae, H. G. Lee, Int. J. Biol. Macromol. 2014, 63, 98.

[31] D. Bath, K. Shelke, R. Hoseney, Cereal Foods World (USA) 1992.

[32] T.-A. Do, J. Vieira, J. Hargreaves, J. Mitchell, B. Wolf, LWT-Food Sci. Technol. 2011, 44, 1207.

[33] B. Dyer, Manuf. Confectioner 2003, 83, 47.

[34] S. Martínez-Cervera, A. Salvador, B. Muguerza, L. Moulay, S. Fiszman, LWT-Food Sci. Technol. 2011, 44, 729.

[35] S. Martínez-Cervera, A. Salvador, T. Sanz, Food Hydrocolloids 2014, $35,1$.

[36] L. Juszczak, T. Witczak, R. Ziobro, J. Korus, E. Cieslik, M Witczak, Carbohydr. Polym. 2012, 90, 353.

[37] V. Psimouli, V. Oreopoulou, J. Food Sci. 2013, 78.

[38] N. Aravind, M. J. Sissons, C. M. Fellows, J. Blazek, E. P. Gilbert, Food Chem. 2012, 132, 993.

[39] M. A. Brennan, J. A. Monro, C. S. Brennan, Int. J. Food Sci. Technol. 2008, 43, 2278.

[40] M. Foschia, D. Peressini, A. Sensidoni, M. A. Brennan, C. S. Brennan, Food Chem. 2015, 172, 245.

[41] M. Alizadeh, M. Azizi-Lalabadi, S. Kheirouri, Food Nutrition Sci. 2014, 5, 390.

[42] M. Carakostas, L. Curry, A. Boileau, D. Brusick, Food Chem. Toxicol. 2008, 46, S1. 